\title{
Characterisation and quantification of regional diurnal SST cycles from SEVIRI
}

\author{
I. Karagali ${ }^{1}$ and J. L. Høyer ${ }^{2}$ \\ ${ }^{1}$ DTU Wind Energy, Technical University of Denmark, Ris $\emptyset$ Campus, Building 125, Roskilde, 4000, Denmark \\ ${ }^{2}$ Centre for Ocean and Ice (COI), Danish Meteorological Institute (DMI), Lyngbyvej 100, 2100, Denmark \\ Correspondence to: I. Karagali (ioka@dtu.dk)
}

Received: 28 January 2014 - Published in Ocean Sci. Discuss.: 7 April 2014

Revised: 19 June 2014 - Accepted: 2 July 2014 - Published: 2 September 2014

\begin{abstract}
Hourly SST (sea surface temperature) fields from the geostationary Spinning Enhanced Visible and Infrared Imager (SEVIRI) offer a unique opportunity for the characterisation and quantification of the diurnal cycle of SST in the Atlantic Ocean, the Mediterranean Sea and the northern European shelf seas. Six years of SST fields from SEVIRI are validated against the Advanced Along-Track Scanning Radiometer (AATSR) Reprocessed for Climate (ARC) data set. The overall SEVIRI-AATSR bias is $-0.07 \mathrm{~K}$, and the standard deviation is $0.51 \mathrm{~K}$, based on more than $53 \times 10^{6}$ matchups. Identification of the diurnal signal requires an SST foundation temperature field representative of well-mixed conditions which typically occur at night-time or under moderate and strong winds. Such fields are generated from the SEVIRI archive and are validated against pre-dawn SEVIRI SSTs and night-time SSTs from drifting buoys. The different methodologies tested for the foundation temperature fields reveal variability introduced by averaging night-time SSTs over many days compared to single-day, pre-dawn values. Diurnal warming is most pronounced in the Mediterranean and Baltic seas while weaker diurnal signals are found in the tropics. Longer diurnal warming duration is identified in the high latitudes compared to the tropics. The maximum monthly mean diurnal signal can be up to $0.5 \mathrm{~K}$ in specific regions.
\end{abstract}

\section{Introduction}

Diurnal warming of the sea surface temperature (SST) occurs under favourable conditions of solar heating and weak winds, and it is most intense in the first few millimetres of the water column; the part observable from microwave and infrared sensors. It has been observed in different areas of the global ocean from the tropics and mid-latitudes (Merchant et al., 2008; Price et al., 1987; Ward, 2006) to higher latitudes (Eastwood et al., 2011; Karagali et al., 2012). Large diurnal warming signals compared to drifting buoys have been reported in the inter-tropical Atlantic, whereas in other regions of the "disc" (i.e. field of view) of the Spinning Enhanced Visible and Infrared Imager (SEVIRI), the agreement between drifters and the satellite diurnal signal was found to be around 0.5 K (Le Borgne et al., 2012b). Castro et al. (2013) used SEVIRI SSTs and unpumped Argo floats to derive diurnal warming estimates, showing a good agreement between the two measuring instruments.

Not accounting for the daily variability in SST may result in biases of the total heat budget estimates (Webster et al., 1996; Ward, 2006; Bellenger and Duvel, 2009; Bellenger et al., 2010). Recently, Clayson and Bogdanoff (2013) estimated that the globally averaged error in the flux calculations due to neglect of the SST diurnal signal is $\sim 4.5 \mathrm{~W} \mathrm{~m}^{-2}$, but on an instantaneous basis, the total error can exceed $200 \mathrm{~W} \mathrm{~m}^{-2}$ in specific locations. Strong SST diurnal signals can complicate the assimilation of SST fields in ocean and atmospheric models, the derivation of atmospheric correction algorithms for satellite radiometers and the merging of satellite SST from different sensors (Donlon et al., 2007). In addition, SST gradients can cause biases in the scatterometerderived ocean winds and in the estimated net flux of $\mathrm{CO}_{2}$, as the outflux of oceanic $\mathrm{CO}_{2}$ is positively correlated with the increase of SST. Understanding the daily SST variability is an ongoing scientific endeavour. Quantifying the diurnal signals of SST at different regions, and resolving the vertical 
extent of the diurnal signal, is important in order to relate observations from different instruments and to remove trends from climate records.

The aim of this study is to thoroughly characterise the regional extent of diurnal SST signals over a range of latitudinal bands. The 6-year-long SEVIRI hourly SST fields are used to perform a low, mid- and high latitude evaluation of the diurnal cycle and identify regional patterns. Identifying areas where common diurnal warming patterns occur is important to better understand the conditions under which the diurnal cycle is formed. Envisat Advanced AlongTrack Scanning Radiometer (AATSR) SSTs hold a key role for comparisons with the SEVIRI SSTs, especially in areas where drifting buoys are not available. Focus is given on the definition of the foundation temperature which must be representative of well-mixed conditions. As the diurnal signal develops on the foundation temperature, an accurate estimation of the latter is required to avoid over- or underestimation of the daily cycle's amplitude.

The satellite and in situ data used in the study are described in Sect. 2, and the methodologies used for the collocation of data sets and the generation of night-time composite SST fields representative of foundation temperatures are presented in Sect. 3. The results in this study are categorised as (i) SEVIRI-AATSR validation statistics found in Sect. 4.1, (ii) sensitivity tests on the night-time composites are presented in Sect. 4.2 and (iii) results on the regional diurnal warming signals can be found in Sect. 4.3. Finally, the discussion regarding the key findings of the study is available in Sect. 5 and conclusions are to be found in Sect. 6.

\section{Data}

\subsection{SEVIRI}

The Meteosat Second Generation (MSG) SEVIRI instrument is in geostationary orbit, centred at $0^{\circ} \mathrm{N}, 0^{\circ} \mathrm{E}$, with a nadir resolution of $3 \mathrm{~km}$. Experimental hourly fields on a $0.05^{\circ}$ grid, from the Centre Météorologie Spatiale (CMS), Météo France, were obtained for the period 2006-2011 in order to analyse the regional diurnal warming in the SEVIRI disc. The selected domain extends from $73^{\circ} \mathrm{W}$ to $45^{\circ} \mathrm{E}$ and $60^{\circ} \mathrm{S}$ to $60^{\circ} \mathrm{N}$. The SEVIRI SSTs are corrected for the cool skin bias by adding $0.2 \mathrm{~K}$ to the original skin retrievals and are therefore representative of sub-skin temperatures (O\&SI SAF, 2006). SEVIRI SST retrievals are classified using a quality flag index of 0 (unprocessed), 1 (erroneous), 2 (bad), 3 (acceptable), 4 (good) and 5 (excellent). In this study, only SEVIRI SSTs flagged with quality 3 or higher were used.

\subsection{AATSR}

The AATSR, with a nadir resolution of $1 \mathrm{~km}$, was on board the polar orbiting ESA Envisat platform, operational from 2002 to 2012. Envisat had the local equatorial crossing time (LECT) at 10:00, crossing from north to south during the descending orbit in daytime and from south to north during the ascending orbit in night-time. The AATSR Re-processing for Climate (ARC) data set v1.1 was obtained for the period January 2006-March 2010 and v1.1.1 from April 2010-December 2011, through the Natural Environment Research Council (NERC) Earth Observation Data Centre (http://www.neodc.rl.ac.uk/browse/neodc/arc). The selected file types are (i) daytime dual-view 2-channel SST retrievals and (ii) night-time dual-view 3-channel SST retrievals. Three different SST measurements are available on a $0.1^{\circ}$ grid, i.e. skin, sub-skin and depth, and an uncertainty flag is included in the file. In this study, we use the AATSR skin measurements that have an uncertainty of $0.8 \mathrm{~K}$ or lower.

\subsection{Drifting buoy data}

Temperature measurements from drifting surface buoys that report observations on an hourly basis are obtained from the Coriolis database (http://www.coriolis.eu.org/), available for the entire Atlantic from 2006 to 2011. The temperature sensor is placed at approximately $20 \mathrm{~cm}$ depth (http://www.jcommops.org/dbcp/community/standards.html) and the observations have an error of about $0.2^{\circ} \mathrm{C}\left(\mathrm{O}^{\prime}\right.$ Carroll et al., 2008).

\section{Methods}

\subsection{SEVIRI-AATSR validation}

The spatial and temporal matching of the SEVIRI-AATSR SSTs is performed based on (i) a maximum 30 min difference between local times, (ii) SEVIRI SST with quality flags $\geq 3$ and AATSR SST with uncertainty $\leq 0.8 \mathrm{~K}$ and (iii) SEVIRIAATSR latitude and longitude difference $\leq 0.049^{\circ}$. To correct for the different reference depth of the AATSR and SEVIRI SSTs (skin vs. sub-skin), $0.2 \mathrm{~K}$ are subtracted from each SEVIRI retrieval only for the validation part of this study, and thus both AATSR and SEVIRI data sets are representative of $\mathrm{SST}_{\text {skin. }}$. The same holds when AATSR and SEVIRI are compared to drifter measurements. To examine the sensitivity of the SEVIRI-AATSR statistics to a varying time window, $5 \mathrm{~min}$ thresholds starting from 0 and up to $30 \mathrm{~min}$ were defined. Statistics were computed for each threshold, using only the SEVIRI-AATSR match-ups with time differences smaller or equal to that threshold. 
Table 1. Description of the parameters used for each one of the test foundation fields (TFF) and the validation field (VF).

\begin{tabular}{llll}
\hline Name & $\begin{array}{l}\text { Averaged days } \\
(\text { day } \pm)\end{array}$ & $\begin{array}{l}\text { Night-time } \\
\text { window (LT) }\end{array}$ & Quality flag \\
\hline TFF1 & $7(3)$ & $00: 00-04: 00$ & $3,4,5$ \\
TFF2 & $1(0)$ & $00: 00-04: 00$ & $1,2,3,4,5$ \\
TFF3 & $1(0)$ & $00: 00-04: 00$ & $3,4,5$ \\
TFF4 & $1(0)$ & $00: 00-04: 00$ & 5 \\
TFF5 & $1(0)$ & $00: 00-06: 00$ & $3,4,5$ \\
VF & $1(0)$ & last pre-dawn & 5 \\
\hline
\end{tabular}

\subsection{SST foundation fields}

In order to study the diurnal SST variability, a foundation $\mathrm{SST}$ field $\left(\mathrm{SST}_{\text {found }}\right)$ representative of well-mixed conditions in the upper oceanic surface layer is necessary. Test foundation fields (abbreviated to TFF) are composed from SEVIRI night-time SSTs for the years 2006-2011 using a local nighttime window, different ranges of the MSG quality flags (abbreviated to QF) and averaging multiple or 1 day SSTs. See Table 1 for a description of the different foundation fields.

Validation fields (VF) are composed daily from the last pre-dawn value, which is considered representative of the coldest SST, flagged with QF 5. The difference TFF-VF is defined and the statistics are computed for each TFF-VF combination. The "successful" TFF must combine low standard deviation and high data availability. For the latter reason, we do not use a combination of only QF 4, 5 for the TFFs, as this would not mitigate the issue of potentially low data availability (see number of available data $N$ shown in Table 2, rows 3-5). Such sensitivity tests aim at investigating the impact of the different foundation fields with respect to latitude. In addition, the Coriolis drifter data are used to generate drifter foundation fields (abbreviated to DTFF) similar to the SEVIRI TFFs for the same period, for comparison.

\section{Results}

\subsection{SEVIRI-AATSR validation}

The verification of the match-up procedure and the sensitivity analysis regarding the time interval between SEVIRI and AATSR retrievals (not shown) indicated a general decrease of the bias and the standard deviation with decreasing time interval. The validation results are presented in terms of the mean bias $(\mu)$, standard deviation $(\sigma)$ and correlation $(r)$ between SEVIRI and AATSR in the top five rows of Table 2. All match-ups satisfy the quality flag and uncertainty criteria. Statistics derived without using any uncertainty flag on the AATSR data produced higher data availability (by approximately $10^{5}$ ) while the mean bias, standard deviation and correlation coefficient remained the same. To
Table 2. Statistics of SEVIRI, AATSR and Drifters. The mean bias is defined as $\mu$, the standard deviation as $\sigma$ and the number of match-ups, $N$. All match-ups are with AATSR uncertainties $\leq 0.8 \mathrm{~K}$ included and the SEVIRI skin correction. Filtered match-ups are based on $\mu$ within the interval $\mu \pm 4 \times \sigma$. The upper five rows show the statistics of SEVIRI-AATSR match-ups. The bottom three rows include the statistics based on the availability of drifting buoys.

\begin{tabular}{lrrrr}
\hline & $\mu$ & $\sigma$ & $r$ & $N$ \\
\hline All & -0.06 & 0.56 & 0.996 & 53393988 \\
Filtered & -0.07 & 0.51 & 0.997 & 53127984 \\
SEVIRI QF 3-AATSR & -0.18 & 0.55 & 0.997 & 22195034 \\
SEVIRI QF 4-AATSR & -0.06 & 0.46 & 0.998 & 7262765 \\
SEVIRI QF 5-AATSR & 0.03 & 0.45 & 0.997 & 23670185 \\
\hline SEVIRI-Drifters & -0.23 & 0.67 & 0.993 & 12849 \\
AATSR-Drifters & -0.16 & 0.51 & 0.996 & 12842 \\
SEVIRI-AATSR & -0.07 & 0.48 & 0.996 & 12926 \\
\hline
\end{tabular}

avoid contamination of spurious SST values, a filter is applied to exclude match-ups outside the interval $\mu \pm 4 \times \sigma$ (rows 2-5).

Filtered match-ups indicate colder SEVIRI SST with $\mu=$ $-0.07 \mathrm{~K}, \sigma=0.51 \mathrm{~K}$ and $r=0.997$. A consistent decrease of $\mu$ and $\sigma$ is observed for increasing SEVIRI quality flags, with only QF 5 data having a positive $\mu$ value. Using the time and space collocation criteria for the existing match-up database of SEVIRI-AATSR, drifting buoy measurements are used as a cross-validation data set. The statistics between SEVIRI, AATSR and drifters are shown in the bottom three rows of Table 2 . Note that the last row is different from rows 1 to 5 in that the SEVIRI-AATSR match-ups have been calculated only where drifting buoy measurements are available, for comparison. Moreover, the SEVIRI QF and AATSR uncertainty values used for the comparisons with the drifting buoys are the same as previously stated. SEVIRIDrifter biases are negative, indicating colder SEVIRI SSTs, justified by the skin vs. $20 \mathrm{~cm}$ depth difference between the two types of observations. Such is the case for the AATSRDrifter bias but the $\mu$ absolute value is lower. The SEVIRIDrifter $\sigma$ is higher than the AATSR-Drifter $\sigma$ and correlation is marginally lower for SEVIRI-Drifter.

Figure 1 shows the $\mu$ and $\sigma$ values of SEVIRI-AATSR filtered match-ups (row 2 of Table 2) binned in $25 \mathrm{~km} \times 25 \mathrm{~km}$ boxes. Negative biases exceeding $-0.5 \mathrm{~K}$ are identified in the tropics and the mid-latitudes of the North Atlantic. The standard deviation is generally less than $0.5 \mathrm{~K}$ for the largest part of the domain except the western border of the disc, associated with the SEVIRI satellite zenith angle and the reduced accuracy due to the large atmospheric path. There is an evident trend of increasing $\sigma$ in the zonal direction from the prime meridian which is not as obvious in the meridional direction from the Equator, at least up to $60^{\circ} \mathrm{N}$. Highest $\sigma$ values are found for the Labrador Sea, i.e the upper left corner of the domain, where SEVIRI SSTs and thus diurnal 
(a)

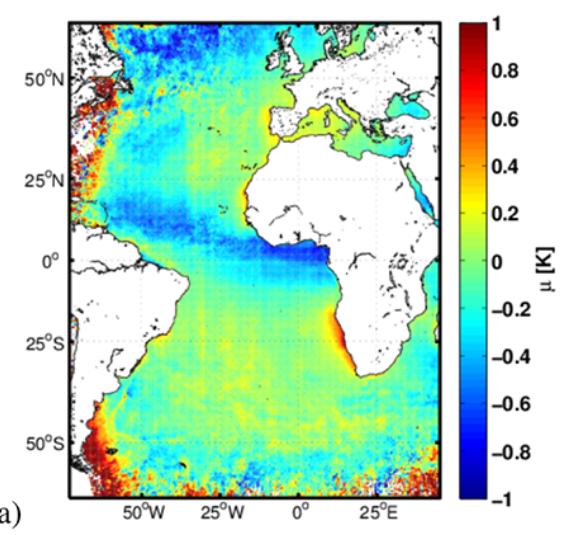

(b)

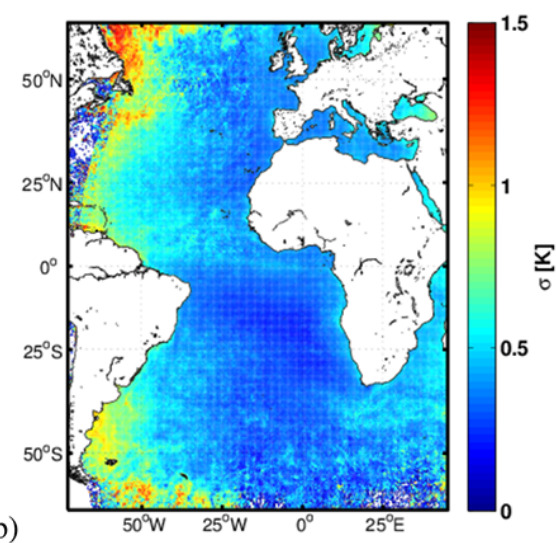

(c)

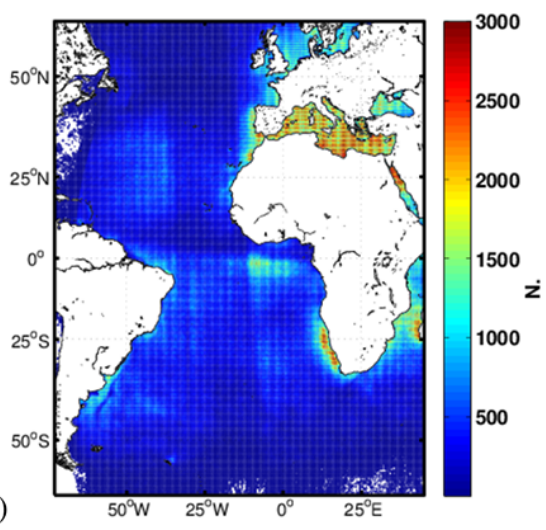

Figure 1. SEVIRI-AATSR (a) mean bias $\mu$, (b) standard deviation $\sigma$, (c) number of match-ups $N$, binned in $25 \mathrm{~km} \times 25 \mathrm{~km}$ boxes.

warming estimates will be more uncertain. Most SEVIRIAATSR match-ups are in the European seas and around southern Africa (Fig. 1c).

The ARC data set has well-documented and low biases of the order of $0.3 \mathrm{~K}$ compared to in situ measurements (Embury et al., 2012). SEVIRI-AATSR biases for the filtered and uncertainty-flagged data sets (see row 2 in Table 2) agree with the biases and $\sigma$ values reported in Le Borgne et al. (2012a) before a bias adjustment was performed using AATSR data. When only quality 5 SEVIRI data are used, $\mu$ and $\sigma$ are of the same order as in Le Borgne et al. (2012a) after the bias adjustment. Daytime vs. night-time SEVIRIAATSR match-ups (not shown) indicate that for local times extending $5 \mathrm{~h}$ around the AATSR equatorial crossing time, i.e. for retrievals near the sub-satellite track, negative biases mostly occur at night-time. From existing results in the literature (Embury et al., 2012; O'Carroll et al., 2008), AATSR night-time retrievals have a lower error compared to daytime. Our larger night-time biases indicate that SEVIRI is even colder at night-time compared to AATSR. Le Borgne et al. (2012b) also reported a higher night-time bias and standard deviation of SEVIRI against drifting buoys and associated it with the SEVIRI cloud mask performance, which is better at daytime due to the use of the SEVIRI high resolution visible channel. This cold bias may arise at night-time, when the visible channel is not available, because the cloud mask may be identifying cloud covered pixels, which have lower temperatures, as cloud free water pixels.

Negative SEVIRI-AATSR biases are mostly confined in the tropics, and in Le Borgne et al. (2011) they were attributed to retrieval algorithm errors caused by the anomalous atmospheric water vapour vertical profiles. The spatial distribution of the SEVIRI-AATSR biases shows strong positive signals around upwelling regions and cold currents (Portugal, Canary, Benguela and Malvinas currents). In such areas the cold water temperatures can cause the atmosphere to be cooler, and thus, with low atmospheric water vapour content. The mechanism of the water vapour impact on SST retrievals, as explained in Le Borgne et al. (2011), dictates than since water vapour generally decreases the brightness temperatures observed by infrared instruments, it results in cool SST biases that are corrected for by the retrieval algorithms. In regions with low water vapour content, such as cold current regions and upwelling areas, an over-correction for water vapour may occur resulting in warmer SSTs, hence the larger positive SEVIRI-AATSR biases. Especially off the coast of Angola/Namibia and north-west Africa, the warm SEVIRI bias may also be associated with an overestimation in the SEVIRI dust index correction. Moreover, for the region of the cold Malvinas Current which is also at the edge of the SEVIRI disc, accuracy is reduced. Similar spatial patterns of 10 day average mean SEVIRI-AATSR differences are reported in Le Borgne et al. (2012a), averaged over boxes of different dimensions (see their Fig. 3).

When SEVIRI and AATSR match-ups are further validated with drifter measurements, it is found that both sensors have a cold bias compared to drifters. Similar results, though slightly lower than what we report here, were found by Le Borgne et al. (2012a); SEVIRI before adjustment had a $\mu$ of $-0.08, \sigma=0.57 \mathrm{~K}$ against AATSR and $\mu=-0.12$, $\sigma=0.56 \mathrm{~K}$ against drifters. Moreover, SEVIRI-Drifter biases reported in Le Borgne et al. (2012b), for 2011-2012, were also marginally lower than what is reported in our study, but the SEVIRI data in their study were subject to a correction using NWP (numerical weather prediction) fields for atmospheric water vapour. Our SEVIRI-Drifter bias and standard deviation are slightly larger than what is reported in Castro et al. (2013) using pumped and unpumped Argo data. This is associated with the higher accuracy and better depth representation of the Argo floats compared to drifters, but also with the 3-hourly SEVIRI product used in that study which will tend to reduce noise in the measurements. The impact of the SEVIRI quality flags in the statistics, found in Castro et al. (2013), indicates a slight increase towards small positive $\mu$ and slight improvement in the $\sigma$ values for QF5 SST, consistent with our findings. 

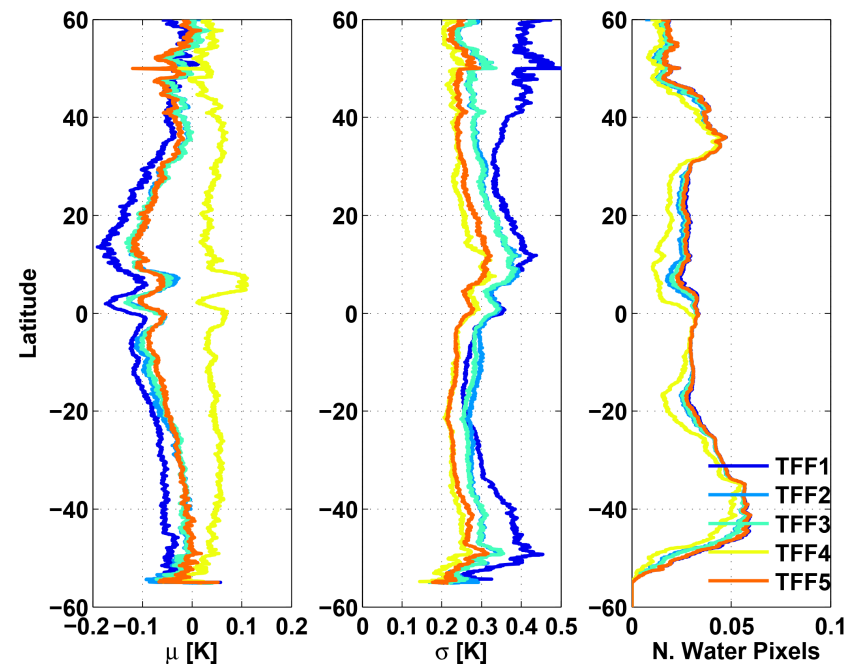

Figure 2. Latitude dependent statistics of TFF-VF for the period 2006-2011.

The SEVIRI processing chain has recently been updated to accommodate retrieval biases at some of the problematic areas mentioned above. The new processing started in 2011 and up to now no re-processing of the SEVIRI archive is being performed, and thus this study uses the old data set. Some of the well-documented biases found in this study are compensated for in the new data set (Le Borgne et al., 2012a). However, since our focus is on reliable diurnal variability results from long and multi-year satellite data, the new data can not be used at this point.

\subsection{Validating test foundation SST fields}

The averaged statistics for all the test foundation fields (TFF) against the validation field (VF) and the drifter test foundation fields (DTFF), are shown in Table 3. The mean bias $(\mu)$ for all the TFFs-VF is almost zero and standard deviation $(\sigma)$ values are mostly less than $0.3 \mathrm{~K}$, while very subtle differences between the TFF are identified. TFF-DTFF $\mu$ and $\sigma$ are slightly higher, showing warmer drifter values; this is related to the cool skin effect, i.e. the increased heat loss to the atmosphere, present in the SEVIRI SST but most likely absent from the drifter measurements which are taken from a reference depth of $20 \mathrm{~cm}$. The lowest absolute mean bias is found for TFF2 and TFF3 against the VF and for TFF4 against DTFF. Standard deviation of the TFF-VF is lowest for TFF4 and TFF5, and for TFF1 when DTFFs are used. The relatively high $\sigma$ values (for TFF-DTFF) are associated with the few night-time drifter data available for the composition of similar foundation fields to the SEVIRI ones, which is also supported by the reduced $\sigma$ found when a multi-day composite (TFF1) is used.

Statistics of the TFF-VF for the entire period 2006-2011, are presented as a function of the latitude in Fig. 2. For all TFF-VF, $\mu$ is negative except for TFF4, which is only composed of quality $5 \mathrm{SST}$ and shows positive $\mu$ mostly around $0.05 \mathrm{~K}$ that only reach up to $0.1 \mathrm{~K}$ north of the Equator. This positive $\mu$ is associated with the quality flag used, as also shown in row 5 of Table 2, but nonetheless that contribution is negligible. Ranging between 0.2 and $0.3 \mathrm{~K}, \sigma$ values are the lowest for TFF4 and TFF5, especially in "noisy" areas such as the higher latitudes of both hemispheres. Nonetheless, only slightly higher $\sigma$ is found for TFF2 and TFF3. The multi-day composite TFF1 (dark blue line) has the highest absolute $\mu$ and $\sigma$, related to averaging over many days. The data availability, defined as the percentage of available data over the total amount of water grid cells in the domain, is slightly reduced when TFF4 is used.

Comparing TFF2 and TFF3, the impact of the quality flags is highlighted as including lower quality data in TFF2 causes slightly higher $\sigma$ compared to TFF3, especially between 30 and $5^{\circ} \mathrm{S}$, and this is explained by the fact that TFF3 is composed only of quality 3 and higher. Comparing TFF3 and TFF5, the impact of the night-time window is revealed as TFF5 has a marginally smaller absolute bias in some latitude bands compared to TFF3 while $\sigma$ is lower by $0.05 \mathrm{~K}$. The slightly improved statistics of TFF5 are related to the longer night-time window (00:00-06:00 LT) that includes the predawn SST value of which VF is composed.

The spatial distribution of the $\mu$, its $\sigma$ and number of match-ups for the period 2006-2011 is shown in Fig. 3 for TFF3-VF. The data availability is defined as the number of available TFF-VF match-ups at each grid cell and the number can not exceed a total of 2190 , i.e. one match-up per day for 6 years. A threshold was applied to avoid spurious SSTs, hence grid cells with less than 10 TFF-VF match-ups are excluded. $\mu$ ranges between -0.1 and $0.1 \mathrm{~K}$ while $\sigma$ values are around $0.3 \mathrm{~K}$ for most parts of the SEVIRI disc. Higher $\mu$ and $\sigma$ are observed in areas with currents, associated with high SST variability, and at the western boundary of the disc.

In summary, the validation of the various night-time SST composites against single-day, pre-dawn SSTs assumed to represent the coldest temperature during a day shows an absolute $\mu$ of the order of $\pm 0.1 \mathrm{~K}$ and $\sigma$ values not exceeding $0.3 \mathrm{~K}$. Thus, the night-time fields can accurately represent cold, night-time foundation temperatures. Using only quality 5 data results in slightly warmer foundation temperatures. This is in accordance with findings from the SEVIRIAATSR validation, which showed that quality 3 or 4 SEVIRI data are colder than quality 5 , and is associated with the cloud masking as lower quality data have higher chances of cloud contamination, i.e. lower pixel SST.

Validation with drifting buoy night-time composites has shown that there is a consistent pattern of colder SEVIRI foundation fields, reaching a maximum of $-0.17 \mathrm{~K}$ due to the difference reference depth. This bias is minimum for TFF4, which consists of only quality 5 SEVIRI SST. Castro et al. (2013) stated that underestimating the SEVIRI foundation fields compared to Argo fields showed a smaller impact on the diurnal warming estimates than overestimating 
Table 3. Averaged statistics of TFF-VF and TFF-DTFF, for the period 2006-2011. The variability from the $N$ of TFF1 is defined as $\frac{N_{\mathrm{TFFX}}-N_{\mathrm{TFF} 1}}{N_{\mathrm{TFF} 1}} \times 100$.

\begin{tabular}{|c|c|c|c|c|c|c|c|c|}
\hline & \multicolumn{2}{|c|}{$\mu[\mathrm{K}]$} & \multicolumn{2}{|c|}{$\sigma[\mathrm{K}]$} & \multicolumn{2}{|c|}{$N$} & \multirow{2}{*}{$\frac{N\left(\times 10^{9}\right)}{\text { TFF }}$} & \multirow{2}{*}{$\frac{\text { Variability from }}{N_{\mathrm{TFF} 1}(\%)}$} \\
\hline & VF & DTFF & VF & DTFF & $\operatorname{VF}\left(\times 10^{9}\right)$ & $\operatorname{DTFF}\left(\times 10^{6}\right)$ & & \\
\hline TFF1 & -0.05 & -0.12 & 0.35 & 0.64 & 0.22 & 3.77 & 3.54 & $0 \%$ \\
\hline TFF2 & -0.01 & -0.16 & 0.30 & 0.73 & 0.18 & 0.15 & 1.09 & $-69.31 \%$ \\
\hline TFF3 & -0.01 & -0.17 & 0.29 & 0.65 & 0.19 & 0.15 & 1.06 & $-69.95 \%$ \\
\hline TFF4 & 0.06 & 0.01 & 0.24 & 0.67 & 0.14 & 0.05 & 0.40 & $-88.51 \%$ \\
\hline TFF5 & -0.02 & -0.17 & 0.25 & 0.67 & 0.21 & 0.24 & 1.26 & $-64.32 \%$ \\
\hline
\end{tabular}

(a)

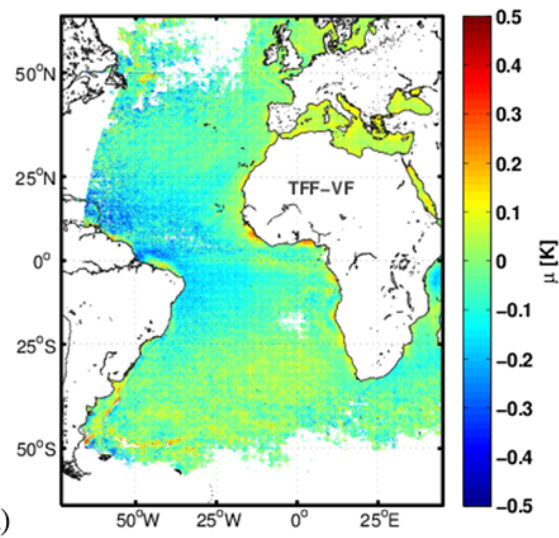

(b)

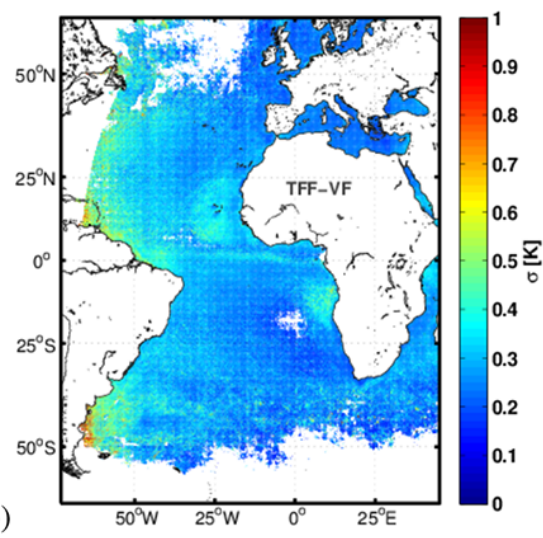

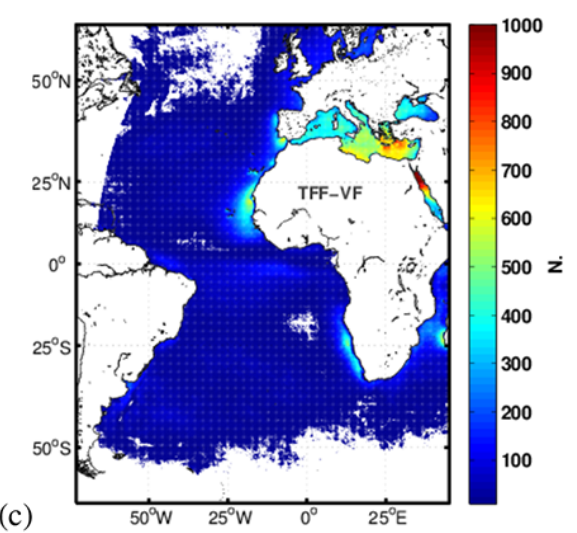

Figure 3. Mean bias $\mu$ (a), standard deviation $\sigma$ (b) and number of match-ups $N$ (c), for the TFF3-VF.

the foundation fields. From results not shown here, it was found that using different foundation fields to obtain diurnal warming estimates does not significantly impact the identified warming, in terms of its amount (in hours), its seasonal and spatial distribution and the peak warming of cases exceeding $2 \mathrm{~K}$. Given the bias statistics, and accounting for low $\mu$ and $\sigma$ combined with a sufficient data availability, TFF3 has been chosen as the foundation field to be used for the regional diurnal warming analysis.

In Le Borgne et al. (2012b), the bias between SEVIRI and drifter foundation fields was $-0.12 \mathrm{~K}$ and the standard deviation $0.39 \mathrm{~K}$, but that study used 1 year of upgraded SEVIRI data with the NWP correction and defined foundation fields from 00:00 LST to sunrise. Foundation fields composed of night-time SEVIRI SSTs from 22:00 to 07:00 local solar time (LST) in Castro et al. (2013) had smaller biases and standard deviations compared to Argo foundation fields than what is presented in this study, which is attributed to the more accurate Argo measurements compared to the drifters and the 3-hourly satellite SST product used. Moreover, they reported slightly smaller biases when only quality 5 data were used with reduced data availability, in accordance with our findings. Finally, for diurnal warming estimates, biases relative to buoys are not a major concern since diurnal warming is estimated from SEVIRI daytime observations vs. SEVIRI foundation fields.

\subsection{Diurnal warming}

The difference, $\delta \mathrm{SST}$, between a given daytime hourly SST value and the corresponding foundation temperature of the previous night is defined as diurnal warming or anomaly. Given the biases and standard deviations found from the validation of the SEVIRI TFFs against Drifter TFFs, a threshold for warming of at least $1 \mathrm{~K}$ or more is used. The spatial extent of anomalies exceeding $1 \mathrm{~K}$, in hours, is presented in Fig. 4a for the period 2006-2011. Areas prone to diurnal warming are the European seas, the Red Sea, the central North and South Atlantic, and the areas of the Malvinas/Brazil currents (SW Atlantic), the Benguela Current offshore from Namibia and Angola (SE Atlantic) and the Mozambique Channel (Indian Ocean). As Fig. 4b shows, most of the quality 5 SST retrievals are also located in these areas. Features such as the mistral wind pattern in the eastern part of the Gulf of Lion and the Etesian (Meltemi) winds in the Aegean Sea, appear as areas of few diurnal warming cases, consistent with what is expected in these areas of strong summer winds.

The spatial extent of cases for which $\delta \mathrm{SST} \leq-1 \mathrm{~K}$ is shown in Fig. $4 \mathrm{c}$ and is considered a measure of random noise and oceanic variability not related to the daily warming cycle, as it represents the occurrences when daytime SST is lower than the night-time foundation field. The occurrence of 

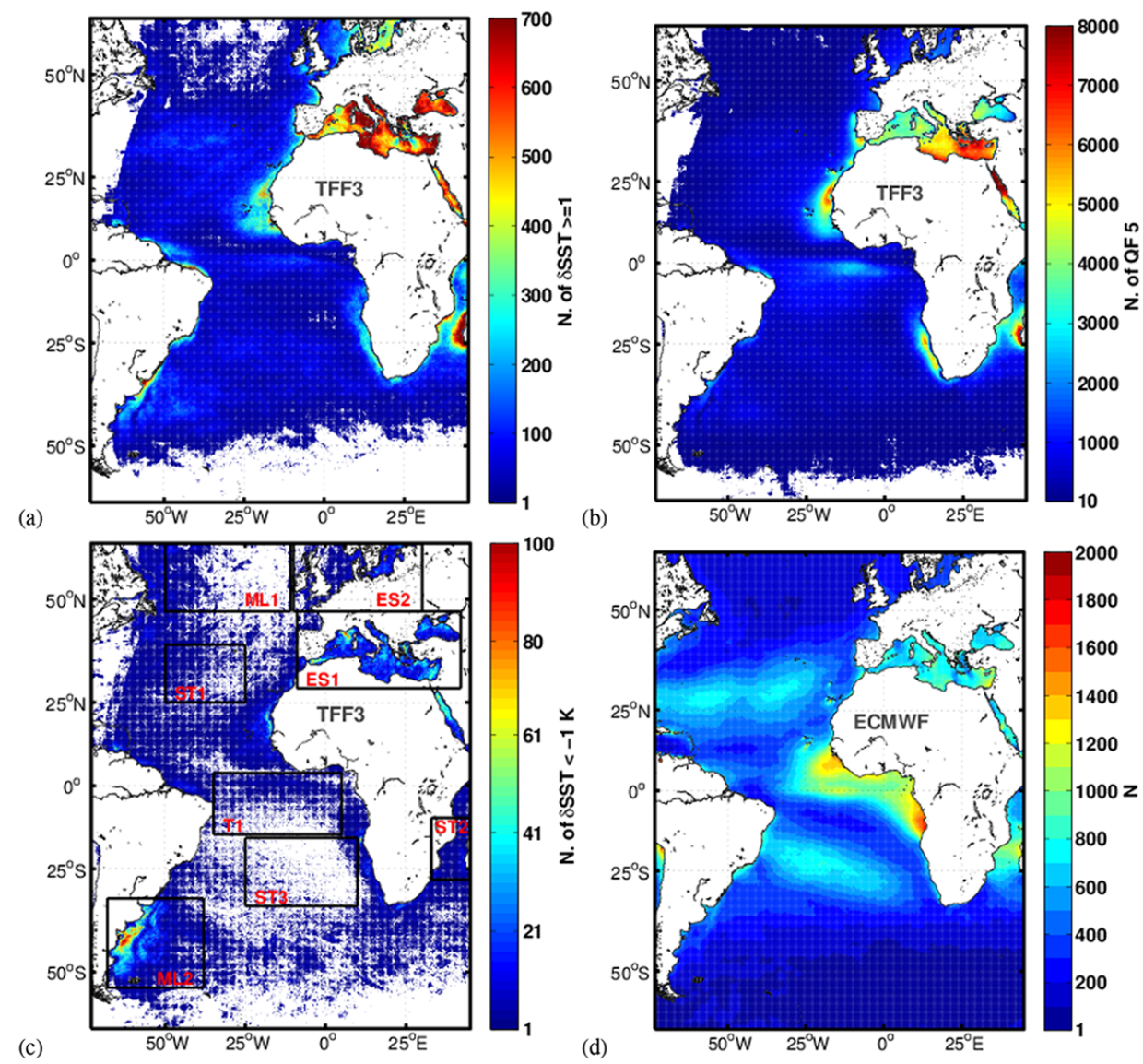

Figure 4. Spatial extent of (a) hours of $\delta$ SST $\geq 1 \mathrm{~K}$ for 2006-2011 where white areas indicate zero occurrences, (b) quality 5 data from $08: 00$ to 22:00 LT and for 2006-2011, (c) number of cases with $\delta$ SST $\leq-1 \mathrm{~K}$ at any time between 08:00 and 22:00 LT for 2006-2011 where zero occurrences are shown as white areas and the domains where regional diurnal warming is studied are plotted as boxes and (d) concurrences of ECMWF wind speed $\leq 6 \mathrm{~m} \mathrm{~s}^{-1}$ and surface net solar flux $\geq 400 \mathrm{~W} \mathrm{~m}^{2}$.

such cases is extremely rare in the entire SEVIRI disc, with the exception of the Malvinas Current region in the western South Atlantic and the eastern Gulf of Lion in the Mediterranean Sea. Areas with some few occurrences include the Alboran Sea (east of the Gibraltar Straight), the Ionian and Levantine seas and the northern Red Sea. In these regions, diurnal warming estimates will have a slightly higher uncertainty compared to other areas but generally negative $\delta \mathrm{SST}$ cases do not exceed 40 occurrences. Strong ocean features such as the Gulf Stream and the Agulhas Current do not appear as areas with negative anomalies, and this is probably related to the fact that SST variability in these areas occurs at longer time-scales.

Using 3-hourly model outputs from the European Centre for Medium-Range Weather Forecasts (ECMWF), the number of concurrent wind speeds $\leq 6 \mathrm{~m} \mathrm{~s}^{-1}$ and insolation $\geq 400 \mathrm{~W} \mathrm{~m}^{-2}$ for the period 2009-2011 was estimated, shown in Fig. 4d. The spatial patterns of high occurrences generally match the diurnal warming patterns. An exception is the area offshore from west Africa, between $15^{\circ} \mathrm{S}$ and $15^{\circ} \mathrm{N}$, where despite the relatively high concurrence of weak winds and strong solar heating, quality $5 \mathrm{SST}$ and $\delta \mathrm{SST} \geq 1 \mathrm{~K}$ are mostly absent. This absence of quality SSTs may be related to the cloud masking scheme. The mismatch between ECMWF low wind/high insolation occurrences and relatively strong diurnal warming signals off the Namibia/Angola coastline is attributed to advection of warm air masses from the nearby continent which can warm up the top layer of the ocean surface. Evidence of this circulation pattern is demonstrated in Richter and Mechoso (2004).

To obtain an estimate of the impact diurnal warming can have on monthly mean SST estimates, the difference $\Delta \mathrm{SST}_{\text {day }}$ is defined as the mean SST during the "day time" (i.e. all SSTs not included in the foundation field) minus the $\mathrm{SST}_{\text {found }}$ of that day. This provides a daily mean diurnal warming estimate which is averaged monthly; thus, 12 mean monthly estimates, $\Delta \mathrm{SST}_{\text {month }}$, are obtained. For each grid cell, the maximum $\Delta \mathrm{SST}_{\text {month }}$ is shown in Fig. 5a, excluding grid cells with less than $10 \Delta \mathrm{SST}_{\text {day }}$ values. The vertical stripes visible in the centre of the disc are an artefact of the 
local timing, as grid cells on the east side of a time zone are at a later time and thus potentially have higher temperatures compared to the ones on the west side of the same time zone.

The figure shows that diurnal warming can have a significant impact on monthly SST estimates, if not accounted for. Average diurnal warming exceeding $0.4 \mathrm{~K}$ is identified in extended parts of the SEVIRI disc, not only in enclosed basins like the Mediterranean, Black, North and Baltic seas but also in open ocean waters. The $\sigma$ of the mean diurnal warming signal is estimated separately in each grid cell from all the $\Delta \mathrm{SST}_{\text {day }}$ of the month with the maximum signal. Figure $5 \mathrm{~b}$ shows values in the range of $0.6-0.8 \mathrm{~K}$ in areas where peak mean diurnal warming is found.

Based on the frequency of $\delta \mathrm{SST} \geq 1 \mathrm{~K}$, eight sub-domains were identified in the SEVIRI disc and are shown in Fig. 4c. They are classified as mid-latitude domains (ML1, ML2), sub-tropics (ST1, ST2, ST3), tropics (T1) and European seas (ES1, ES2). Diurnal warming was studied in these regions in terms of the monthly distribution exceeding some thresholds, the mean local time of occurrence, the distribution of $\delta \mathrm{SST} \geq 2 \mathrm{~K}$, the duration of warming and the average monthly cycles.

Only for the cases with $\delta \mathrm{SST} \geq 2 \mathrm{~K}$, Table 4 shows the 75 th and 95 th percentile $\delta$ SST values and their duration. The 75 th percentiles vary little between domains and range from 2.6 to $2.9 \mathrm{~K}$ but the $95 \%$ have a wider distribution, from $3.2 \mathrm{~K}$ in the tropics to $4.0 \mathrm{~K}$ in the higher mid-latitudes of the Northern Hemisphere. In particular, domains ML1 and ES2 show almost the same percentiles of high warming cases even though Fig. 4a suggests a dramatic decrease in identified warming on ML1 compared to ES2. In almost all domains, $75 \%$ of the cases exceeding $2 \mathrm{~K}$ do not last more than $3 \mathrm{~h}$, with the exception of the tropics and sub-tropics where the 75 th percentile is lowered to $2 \mathrm{~h}$ and the North/Baltic seas, where it increases to $4 \mathrm{~h}$. Similar is the case for the 95 th percentiles, ranging from $4 \mathrm{~h}$ close to the Equator to $6 \mathrm{~h}$ in the mid-latitudes but reaching up to $9 \mathrm{~h}$ in the North/Baltic seas.

\subsubsection{Mid-latitudes}

Monthly distributions of $\delta \mathrm{SST} \geq 1,2$ and $3 \mathrm{~K}$ for domains ML1 and ML2 are shown in Fig. 6a and b. Most $\delta$ SST cases occur during the Northern and Southern Hemisphere summers. In domain ML1 the distribution has a main peak in June and July. Domain ML2 has a less varied signal, as 12$14 \%$ of $\delta \mathrm{SST} \geq 1$ occur from November to February.

The distributions for the local time of $\delta S S T \geq 2 \mathrm{~K}$ occurrences, in Fig. 7a and b, have a peak at 15:00 LST. Both areas are geographically located in the upper mid-latitudes of the North and South Atlantic, where during summer the long period of sunlight drives early warming, more pronounced in domain ML1 compared to ML2.

Averaged hourly diurnal cycles are calculated from grid cells where $\delta$ SST exceeds $0.5 \mathrm{~K}$ at least once during the day. In each domain, the averaged diurnal cycles of the
4 months with the highest number of recorded $\delta \mathrm{SST} \geq 2 \mathrm{~K}$ are shown in Fig. 8. The averaged daily cycle in domain ML1 (Fig. 8a) shows a peak of $\sim 1.2 \mathrm{~K}$. Minimum values are $0.1 \mathrm{~K}$ higher than the foundation temperature between midnight and 02:00 LST, with warming already starting after that point. A smooth warming peaking between 14:0017:00 LST is observed but cooling occurs faster. Domain ML2 (Fig. 8b) has a smoother cycle with a lower peak for all selected months. The morning minimum between 02:00 and 03:00 LST almost reaches foundation temperature values while peak warming occurs between 14:00-16:00 LST. Residual warming of $0.4-0.6 \mathrm{~K}$ is observed in both domains, but particularly for ML1 results are ambiguous as the amount of $\delta \mathrm{SST} \geq 1 \mathrm{~K}$ is limited.

\subsubsection{Sub-tropics}

The monthly distribution of $\delta$ SST exceeding different thresholds indicates that in the North Atlantic domain ST1 (Fig. 6c), a clear seasonal signal exists with a peak of $\delta$ SST in June, and almost no cases exceeding $2 \mathrm{~K}$ for the period October-February. South Atlantic domain ST2 (Fig. 6d) has in total a high number of $\delta \mathrm{SST} \geq 1$ between November and February, reaching up to $17 \%$ in December and January. Cases with $\delta$ SST $\geq 1$ decrease significantly between May and August while no more than $2 \%$ of the cases exceed $2 \mathrm{~K}$ from March to October. Similar is the pattern for domain ST3 (Fig. 6e) but with lower percentages and a secondary peak in October.

Warming exceeding $2 \mathrm{~K}$ peaks in all three domains at 14:00 LST (Fig. 7c-e), with almost no differences at the start of the cycle. In all three domains warming may last up to 23:00 LST, slightly more pronounced in South Atlantic ST2, where more warming occurs compared to the other domains (see Fig. 4a).

This is confirmed by the monthly average diurnal cycles shown in Fig. 8. Domain ST1, in Fig. 8c, shows a very stable cycle throughout the months, with a morning minimum around 04:00 LST and a peak of $1 \mathrm{~K}$ occurring at 14:00 LST. Cooling occurs smoothly and a residual warm layer of $0.4 \mathrm{~K}$ is observed as the temperature at night-time does not return to the pre-warming value. Domain ST2 (Fig. 8d) shows a nighttime cooling that reaches a minimum at 03:00 LST and remains at minimum until 06:00 LST, being slightly colder than the foundation temperature. The peak warming ranges between 1 and $1.2 \mathrm{~K}$, depending on the month, occurring between 14:00-15:00 LST. ST3 (Fig 8e) has similarities with both ST1 and ST2, showing a long morning minimum period around the foundation temperature value and rapid cooling. It is subject to a higher peak $\delta$ SST that varies depending on the month. In all domains, a residual warm layer of $0.3-0.4 \mathrm{~K}$ is observed. 

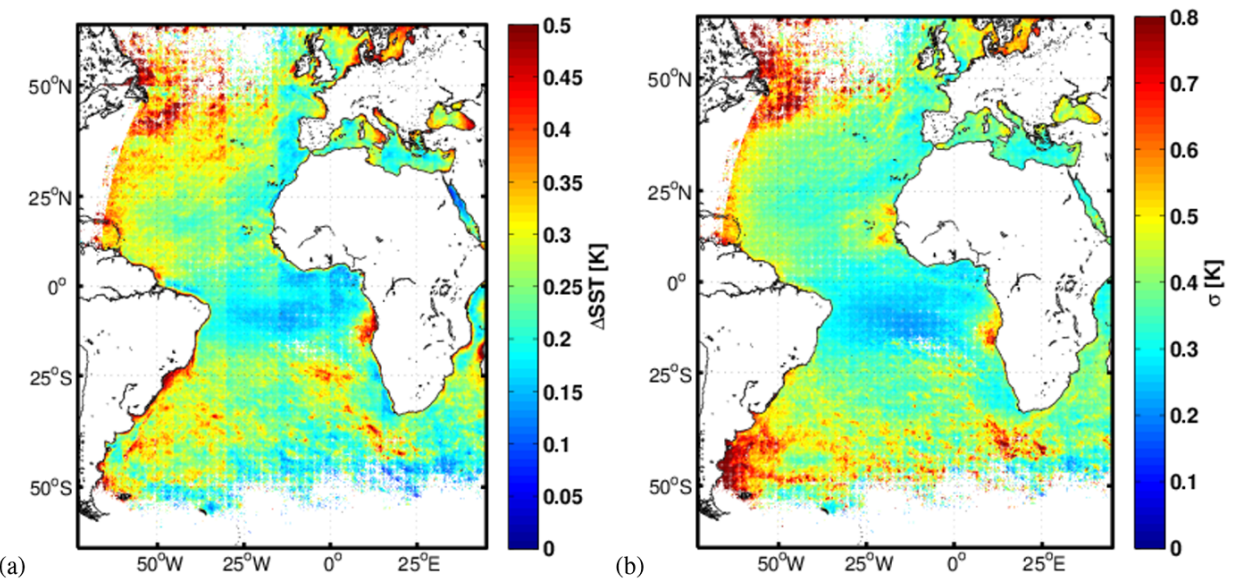

Figure 5. Spatial extent of (a) $\Delta \mathrm{SST}$, defined as the maximum of the monthly averaged $\Delta \mathrm{SST}_{\text {day }}$, i.e. the mean $\mathrm{SST}_{\text {day }}-\mathrm{SST}_{\text {found }}$, where white areas indicate less than $10 \Delta \mathrm{SST}_{\text {day }}$ values, (b) $\sigma$ of the $\Delta \mathrm{SST}_{\text {day }}$ during the month when $\Delta \mathrm{SST}$ occurs.

Table 4. Percentiles of $\delta S S T \geq 2 \mathrm{~K}$ and its duration (in hours), for the different domains.

\begin{tabular}{lrrrrr}
\hline & \multicolumn{2}{c}{$\delta$ SST $\geq 2 \mathrm{~K}$} & & \multicolumn{2}{c}{ Duration (hours) } \\
\cline { 2 - 3 } \cline { 6 - 6 } & $75 \%$ & $95 \%$ & & $75 \%$ & $95 \%$ \\
\hline ML1 & 2.9 & 4.0 & & 3 & 7 \\
ML2 & 2.7 & 3.7 & & 3 & 7 \\
ST1 & 2.7 & 3.3 & & 3 & 5 \\
ST2 & 2.6 & 3.3 & & 2 & 5 \\
ST3 & 2.8 & 3.7 & & 3 & 4 \\
T1 & 2.6 & 3.2 & & 2 & 5 \\
ES1 & 2.8 & 3.7 & & 3 & 5 \\
ES2 & 2.8 & 3.9 & & 4 & 9 \\
\hline
\end{tabular}

\subsubsection{Tropics}

The tropical domain (T1) is the region with an almost nonexistent seasonal variability, a constant $2-3 \%$ of $\delta \mathrm{SST} \geq 1 \mathrm{~K}$ during the year and only very few cases of $\delta \mathrm{SST} \geq 2 \mathrm{~K}$ (Fig. 6f). The few $\delta S S T \geq 2 \mathrm{~K}$ cases start at $\sim 08: 00 \mathrm{LST}$, peak at 14:00 LST (Fig. 7f) and last until late at night. The averaged monthly cycle, shown in Fig. 8f, shows a very smooth warming from the morning minimum at 01:00-02:00 LST to a peak of $0.6 \mathrm{~K}$ at 14:00 LST. Some changes are observed depending on the month; warming starts earlier in April and May, the morning minimum is longer and more pronounced in February and March and the peak is slightly higher and occurs later compared to the April-May case. Cooling generally occurs slowly and the late night temperature decreases to almost pre-warming levels.

\subsubsection{European seas}

A clear seasonal trend is revealed in the Mediterranean/Black Sea domain (Fig. 6g), with a peak in $\delta \mathrm{SST} \geq 1 \mathrm{~K}$ during
May approaching $10 \%$ of the quality 5 SSTs. The frequency of $\delta \mathrm{SST} \geq 2 \mathrm{~K}$ is almost constant from May to July. The North/Baltic seas domain has a more prominent seasonal signal for all thresholds, with a distinct peak in June (Fig. 6h). Cases of $\delta \mathrm{SST} \geq 2 \mathrm{~K}$ reach up to $4 \%$ of the total quality 5 SSTs, the highest percentage of all domains.

The local time of occurrence shows a shift between the two domains, as the prime time for warming in ES1 is 13:00 LST (Fig. 7g), with practically no occurrences before 09:00. Domain ES2 has a wider distribution in the time of occurrence (Fig. 7h), with a peak at 16:00 LST and cases as early as 08:00 LST.

The monthly average diurnal cycle in domain ES1, shown in Fig. 8g, has a prominent night-time cooling resulting in a negative minimum at 05:00 LST, showing that early morning SST can be colder than the $\mathrm{SST}_{\text {found }}$. Warming is fast and the peak value changes depending on the month, reaching a maximum up to $1.3 \mathrm{~K}$ in May. A residual warm layer of $0.4-0.5 \mathrm{~K}$ is maintained independent of the month. At higher latitudes, domain ES2 also has a morning cooling period that results in negative anomalies only during June and July, but lasts for a shorter period, peaks at 04:00 LST and is completely suppressed in May and August (Fig. 8h). Peak warming reaches $1.4 \mathrm{~K}$ in June but it varies depending on the month and in August, the peak value is $0.9 \mathrm{~K}$. A residual warm layer ranging from $0.5-0.6 \mathrm{~K}$ in May and August, to $0.7 \mathrm{~K}$ in June and July is present.

\section{Discussion and summary}

The main focus of this study is to characterise regional diurnal warming on the SEVIRI disc. In order to obtain accurate and trustworthy diurnal estimates, SEVIRI SSTs were validated against AATSR SST retrievals, highlighting regions where SEVIRI retrievals are of high quality but also regions 

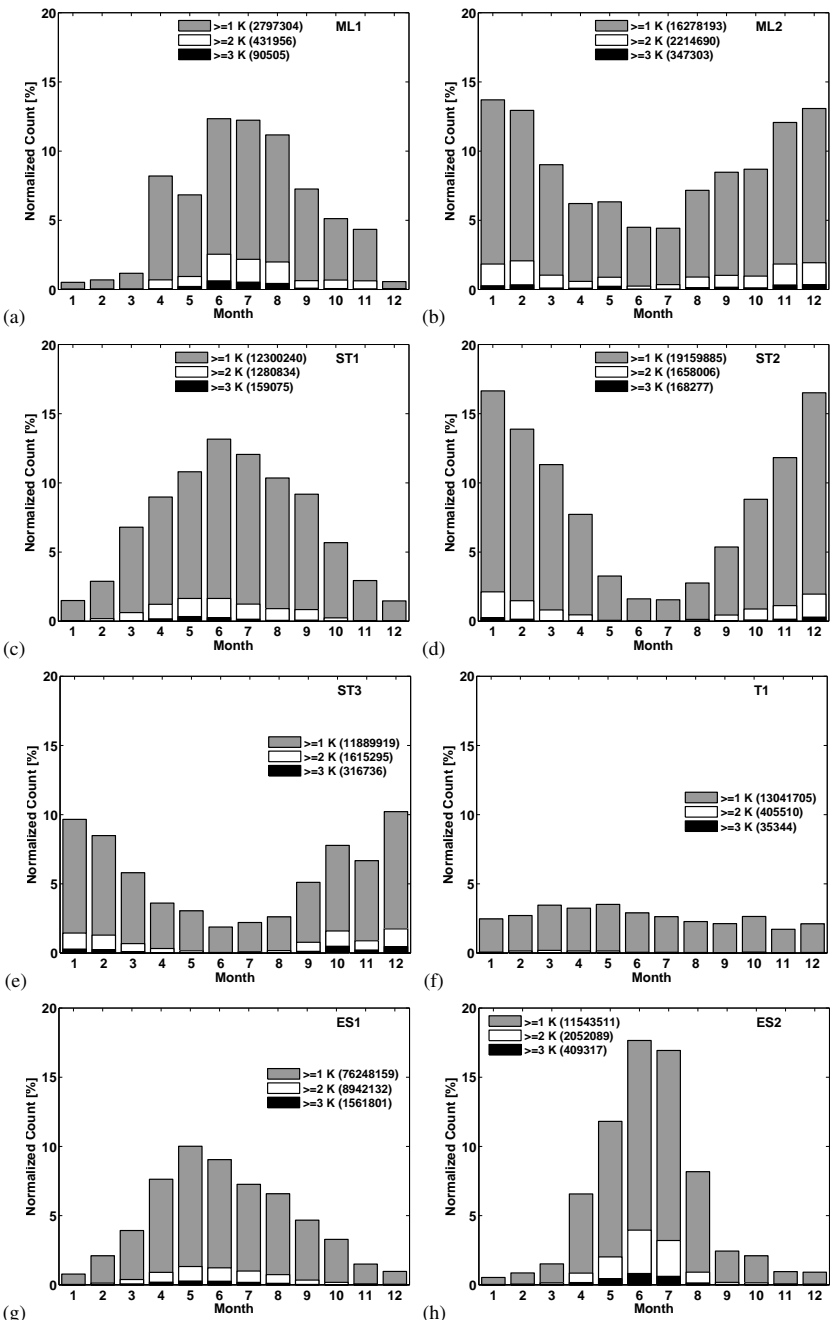

Figure 6. Monthly distribution of hourly $\delta$ SST exceeding 1, 2 and $3 \mathrm{~K}$ from 2006-2011, normalised over the total number of quality 5 SST per month in domains: (a) ML1, (b) ML2, (c) ST1, (d) ST2, (e) ST3, (f) T1, (g) ES1 and (h) ES2.

where diurnal signals will be noisy and thus uncertain. In particular, a zonal increase of the SEVIRI-AATSR standard deviation with distance from the prime meridian is observed, associated with the SEVIRI reduced retrieval accuracy due to the larger atmospheric path, but this is not as obvious in the meridional direction as the distance from the Equator increases. Prior to the estimation of the daily signal, a detailed analysis on the impact of the foundation field was performed. It has been shown that the foundation fields generated from night-time SEVIRI SSTs are representative of well-mixed conditions and thus are appropriately used as the basis upon which the diurnal cycle is developed.

Until now, no systematic investigation has been performed on the derivation of representative foundation fields. Studies mentioned previously generally utilise night-time SSTs of varying quality flags and time-windows, and compare the
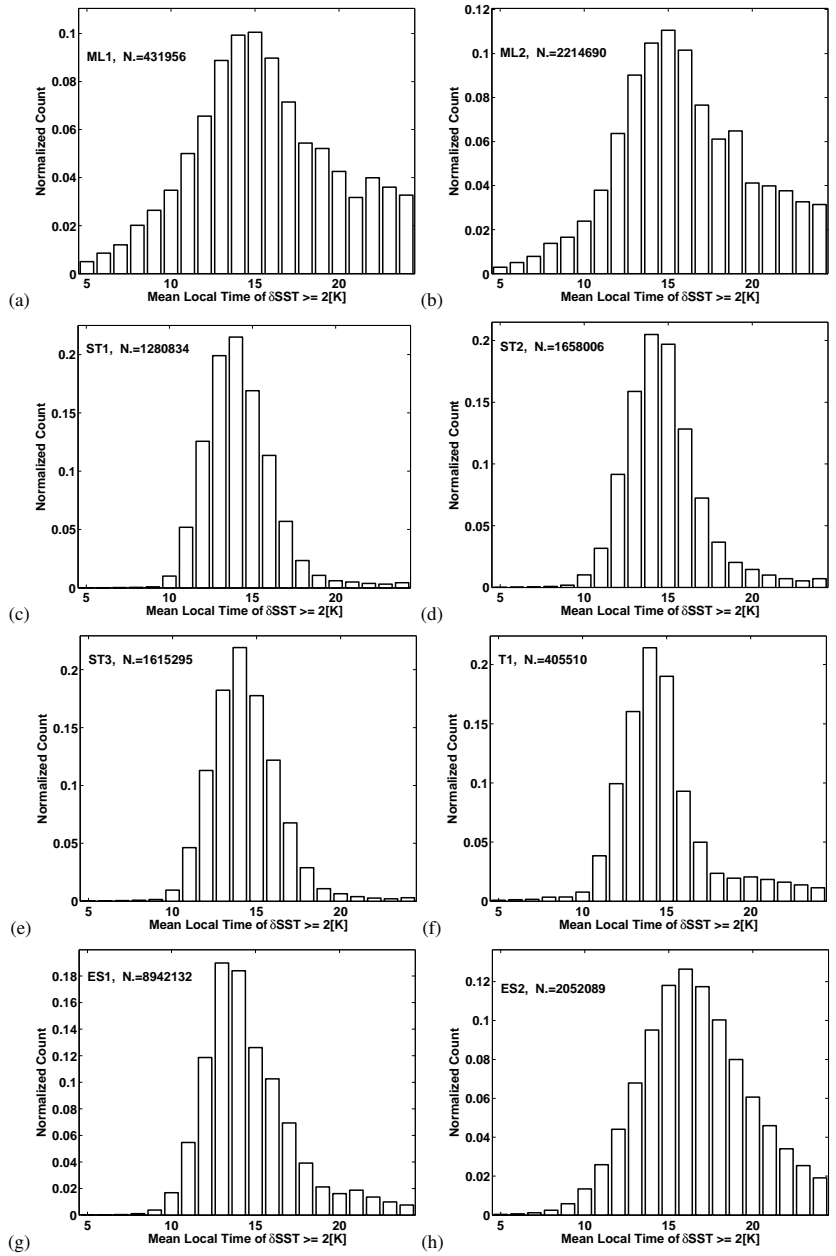

Figure 7. Distribution of mean local time for $\delta S S T \geq 2 \mathrm{~K}$, in different domains of the SEVIRI disc: (a) ML1, (b) ML2, (c) ST1, (d) ST2, (e) ST3, (f) T1, (g) ES1 and (h) ES2.

composites with in situ measurements. In this study, a thorough sensitivity test was performed, by generating various foundation fields and validating them with pre-dawn satellite SSTs and drifting buoy measurements. It was shown that marginally better statistics are obtained when using only quality 5 data but availability is reduced. In addition, averaging over many days results in more gap-free foundation fields but it also introduces more variability, as shown from the increasing $\sigma$ values. Finally, longer night-time windows do not necessarily guarantee more data availability while statistics remain the same, but during summer at high-latitudes some daytime SSTs will be included due to the long daytime period.

Diurnal warming was identified in large areas of the SEVIRI disc, particularly in enclosed seas but also the open ocean while a somewhat suppressed cycle was found in the intertropics. This latter finding may be related to the physical conditions prevailing outside of the Inter-Tropical Convergence Zone (ITCZ), characterised by high and relatively 
(a)

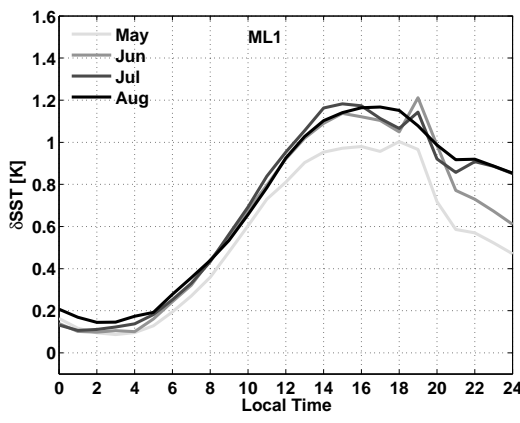

(b)
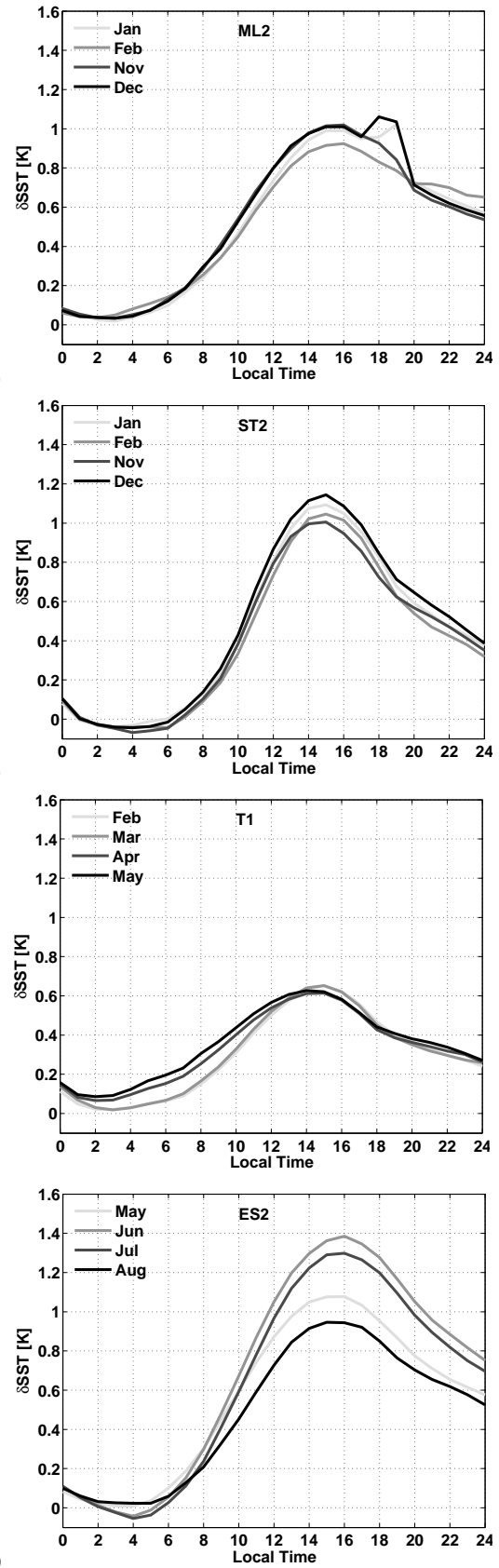

(g)

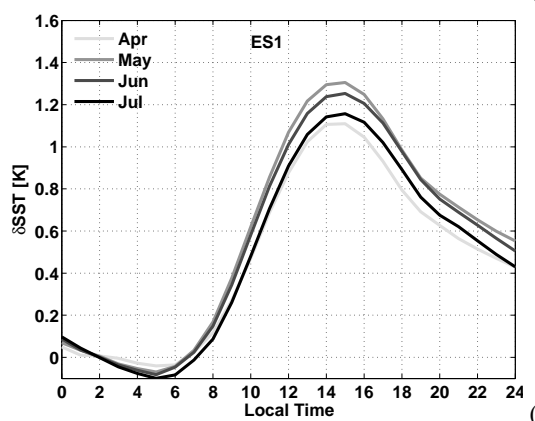

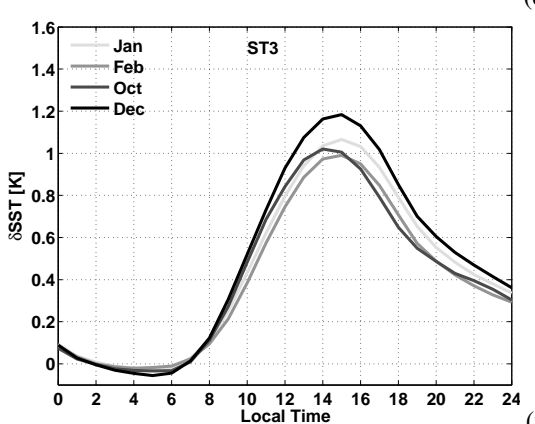

(h)

Figure 8. Monthly averaged daily cycles in different domains of the SEVIRI disc: (a) ML1, (b) ML2, (c) ST1, (d) ST2, (e) ST3, (f) T1, (g) ES1 and (h) ES2. In each domain, the 4 months with the highest number of recorded $\delta$ SST are shown. The daily cycle is produced by hourly averaging grid cells that show $\delta \mathrm{SST} \geq 0.5 \mathrm{~K}$ at least once during the day. A zero value indicates that the hourly SST value is equal to the foundation temperature value. If the temperature at the end of the cycle does not approach the pre-warming value, a residual warm layer exists.

stable water temperature, constant trade winds, convection and high precipitation rates. Nonetheless, a large area off the western Sahara showed relatively strong diurnal warming signals. Since the SEVIRI-AATSR differences are very low in this area, SEVIRI is considered accurate there. Thus, it is postulated that the very high water turbidity, verified by composite maps from the GlobColour project (Morel et al., 2007), reduces the incoming solar radiation's penetration depth in the water column thus strengthening the top layer warming. 
The characteristics of the diurnal cycle differ depending on the region, in terms of the seasonal distribution, the amount of warming exceeding certain thresholds, the peak local time of occurrence and the average monthly diurnal cycle. Consistent findings include the occurrence during the spring/summer months in each hemisphere, a dramatic difference between identified $\delta$ SST exceeding 1 and $2 \mathrm{~K}$, a peak occurring a few hours after local noon with the exact timing shifting towards later hours with increasing latitude, an early morning cool period and a residual warm layer at night-time. Results from Le Borgne et al. (2012b) using 1 year of the upgraded hourly SEVIRI SST over the entire Atlantic indicated a diurnal cycle showing a morning cooling period with a minimum around 06:00 LST, a warming period peaking at 15:00 LST and a residual night-time warm layer smaller than $0.5 \mathrm{~K}$. Our results generally agree, but being area specific, they show that the morning minimum is more pronounced in the mid-latitudes compared to the sub-tropics and that the cycle may reach a peak of $1.4 \mathrm{~K}$ in the North/Baltic seas, compared to a moderate $0.6 \mathrm{~K}$ in the tropics.

Peak monthly diurnal warming of $0.3 \mathrm{~K}$ was identified in extended areas of the Atlantic Ocean and the European seas, but estimates up to $0.5 \mathrm{~K}$ were also found. Peak diurnal warming over a 3-year period, as shown in Castro et al. (2013), had similar spatial distributions as in our study but higher values were recorded. Kennedy et al. (2007) calculated a climatology of diurnal warming estimates from drifting buoy data expanding from 1990 to 2004, where annual average warming patterns and spatial distributions were similar to our findings. However, the dense coverage of the SEVIRI observations provides more detailed estimates of the spatial and temporal variability of the diurnal warming events.

Prytherch et al. (2013) in five mooring sites, mostly out of our domain, observed mean diurnal warming of the same order as reported here. Specifically for a station in the Red Sea and for 2 years of observed temperatures, they stated a mean maximum warming of $0.43 \mathrm{~K}$ while findings from our Fig. 5 indicate a $\triangle S S T$ of $0.17 \mathrm{~K}$ which reaches up to $0.5 \mathrm{~K}$ when $\sigma$ is added. In the Mediterranean Sea, Marullo et al. (2014) computed mean diurnal cycles for 3 months in the summer of 2011 showing a SEVIRI peak warming of $\sim 1.2 \mathrm{~K}$ occurring at 15:00-16:00 LST, very much in agreement with our study despite the differences arising from the newly processed SEVIRI data set used, their much shorter period of study and their averaging over all the summer months to produce the daily cycle.

Such findings provide good arguments regarding the validity of our results. Nonetheless, SEVIRI SSTs can be biased cold in areas with anomalous atmospheric profiles. Subpixel clouds generated during the afternoon will have a similar cold effect, of the order of $0.2 \mathrm{~K}$, on the diurnal warming estimates particularly for large signals, as demonstrated in Le Borgne et al. (2012b). Increased afternoon convection when diurnal layers are created has also been reported by
Bellenger et al. (2010). Using the newly processed SEVIRI archive of SST including the NWP model correction for water vapour (Le Borgne et al., 2011) may provide some different results regarding the derived diurnal warming estimates from the updated SEVIRI data. Nonetheless, it is justified to assume that changes in the general spatial distribution, the timing and magnitude of the signal are expected to be minor. Therefore, results from this study provide a first and reliable description of the diurnal cycle characteristics over several domains and can be useful for satellite SST users that wish to account for or model the diurnal signals in their areas of interest.

\section{Conclusions}

A comprehensive description of diurnal warming estimates in the Atlantic Ocean and the European Seas is presented, based on 6 years of hourly SST observations. In addition, an extensive sensitivity analysis on the definition of foundation temperature fields is performed to evaluate the impact on the diurnal variability estimates. Finally, SEVIRI data are compared with the AATSR re-processed for climate archive (ARC) to establish a quality control on the geostationary sensor which, particularly at large angles, has lower accuracy and resolution. The mean SEVIRI-AATSR bias is $-0.07 \mathrm{~K}$ with a standard deviation of $0.51 \mathrm{~K}$. In the mid-latitudes of both hemispheres, SEVIRI-AATSR biases are almost zero and the standard deviation shows minimum values; in the tropics and high latitudes the bias becomes negative.

Prior to the estimation of diurnal signals, test foundation SST fields are composed from SEVIRI night-time SSTs and are validated against SEVIRI pre-dawn SSTs and nighttime composites from drifting buoys. The validation of SEVIRI foundation fields against pre-dawn SSTs shows almost zero bias and standard deviations of $0.3 \mathrm{~K}$ indicating a good description of night-time, mixed conditions. Validated with drifter composites, it is found that SEVIRI foundation fields are, on average, slightly colder. Generally higher $\sigma$ values are observed in areas with currents associated with high SST variability and at the western boundary of the SEVIRI disc. However, for diurnal warming estimates, biases relative to buoys are not a major concern as the diurnal warming results are derived from SEVIRI daytime observations vs. SEVIRI foundation fields.

An impact of the SEVIRI quality flags is identified, where quality 5 data are warmer and show better statistics with drifter composites. Thus, the SEVIRI-Drifter differences are partly associated with the possible partial cloud coverage of SEVIRI pixels for qualities of 4 and lower. Another bias contribution arises from the reference depth of drifting buoys $(\sim 20 \mathrm{~cm})$ and SEVIRI SSTs (sub-skin estimated as skin $+0.2 \mathrm{~K}$ ). Cool skin effects are largest for weak winds, which is also the case for diurnal warming events. The impact of the large skin effect would be to reduce diurnal warming due 
to heat loss to the atmosphere. Sub-pixel clouds generated during the afternoon will have a similar cold effect. These factors suggest that our diurnal warming estimates may be conservative regarding the peak value and offset.

Diurnal warming estimates extend over the entire SEVIRI disc and generally match well with the spatial pattern of the regions with low wind and high insolation from ECMWF fields. The impact of diurnal variability on monthly mean SST estimates is assessed for the full study area. The maximum monthly mean influence from diurnal variability reaches up to $0.5 \mathrm{~K}$ in extended areas of the SEVIRI disc, mostly confined close to continents and in enclosed seas. Consistent patterns between the diurnal warming estimates include the seasonality of the signal being constrained by the spring/summer season, the morning cooling and residual warm layer. But regional differences in the warming patterns are also identified, particularly regarding the warming thresholds, peak values and timing. It is outside the scope of the present paper to investigate in detail the mechanisms that lead to such regional differences in the diurnal cycle. Water turbidity may hold a role in promoting the development of a diurnal layer, a topic which merits further investigation. Future work will focus on reproducing the observed diurnal variability using a 1-D turbulence model, which allows for the selection of different light absorption schemes, amongst others. This will allow identification of the dominating terms in the ocean and atmospheric heat fluxes for each of the regions.

Acknowledgements. This study was funded by the ESA STSE SSTDV: R.EX.-IM.A.M project, supporting Ioanna Karagali. Jacob Høyer was partly supported by the Sargasso Eel project, funded by the Carlsberg Foundation. SEVIRI data were processed by the Centre de Météorolgie Spatiale, Météo France and the OSI-SAF project.

Edited by: J. M. Huthnance

\section{References}

Bellenger, H. and Duvel, J. P.: An analysis of ocean diurnal warm layers over tropical oceans, J. Climate, 22, 3629-3646, 2009.

Bellenger, H., Takayabu, Y. N., Ushiyama, T., and Yoneyama, K.: Role of diurnal warm layers in the diurnal cycle of convection over the tropical Indian Ocean during MISMO, Mon. Weather Rev., 138, 2426-2433, 2010.

Castro, S., Wick, G., and Buck, J. J. H.: Comparison of diurnal warming estimates from unpumped ARGO data and SEVIRI satellite observations, Remote Sens. Environ., 140, 789-799, 2014.

Clayson, C. A. and Bogdanoff, A. S.: The effect of diurnal sea surface temperature warming on climatological air-sea fluxes, J. Climate, 26, 2546-2556, 2013.

Donlon, C., Robinson, I., Casey, K. S., Vasquez-Cuervo, J., Armstrong, E., Arino, O., Gentemann, C., May, D., LeBorgne, P., Piollé, J., Barton, I., Beggs, H., Poulter, D. J. S., Merchant, C. J.,
Bingham, A., Heinz, S., Harris, A., Wick, G., Emery, B., Minnett, P., Evans, R., Llewellyn-Jones, D., Mutlow, C., Reynolds, R. W., Kawamura, H., and Rayner, N.: The global ocean data assimilation experiment high-resolution sea surface temperature pilot project, B. Am. Meteorol. Soc., 88, 1197-1213, 2007.

Eastwood, S., Le Borgne, P., Péré, S., and Poulter, D.: Diurnal variability in sea surface temperature in the Arctic, Remote Sens. Environ., 115, 2594-2602, 2011.

Embury, O., Merchant, C. J., and Corlett, G. K.: A reprocessing for climate of sea surface temperature from the along-track scanning radiometers: initial validation, accounting for skin and diurnal variability effects, Remote Sens. Environ., 116, 62-78, 2012.

Filipiak, M. J., Merchant, C. J., Kettle, H., and Le Borgne, P.: An empirical model for the statistics of sea surface diurnal warming, Ocean Sci., 8, 197-209, doi:10.5194/os-8-197-2012, 2012.

Karagali, I. and Høyer, J.: Observations and modelling of the diurnal SST cycle in the North and Baltic Seas, J. Geophys. Res.Oceans 118, 1-16, 2013.

Karagali, I., Hoeyer, J., and Hasager, C. B.: SST diurnal variability in the North Sea and the Baltic Sea, Remote Sens. Environ., 112, 159-170, 2012.

Kennedy, J. J., Brohan, P., and Tett, S. F. B.: A global climatology of the diurnal variations in sea-surface temperature and implications for MSU temperature trends, Geophys. Res. Lett. 34, L05712, doi:10.1029/2006GL028920, 2007.

Le Borgne, P., Roquet, H., and Merchant, C. J.: Estimation of sea surface temperature from the spinning enhanced visible and infrared imager improved using numerical weather prediction, Remote Sens. Environ., 115, 55-65, 2011.

Le Borgne, P., Marsouin, A., Orain, F., and Roquet, H.: Operational Sea Surface Temperature bias adjustment using AATSR data, Remote Sens. Environ., 116, 93-106, 2012a.

Le Borgne, P., Legendre, G., and Péré, S.: Comparison of MSG/SEVIRI and drifting buoy derived diurnal warming estimates, Remote Sens. Environ., 124, 622-626, 2012 b.

Marullo, S., Santoleri, R., Ciani, D., Le Borgne, P., Péré, S., Pinardi, N., Tonani, M., and Nardone, G.: Combining model and geostationary satellite data to reconstruct hourly SST field over the Mediterranean Sea, Remote Sens. Environ., 146, 11-23, 2014.

Merchant, C. J., Filipiak, M. J., Le Borgne, P., Roquet, H., Autret, E., Piollé, J.-F., and Lavender, S.: Diurnal warm-layer events in the western Mediterranean and European shelf seas, Geophys. Res. Lett., 35, L04601, doi:10.1029/2007GL033071, 2008.

Morel, A., Huot, Y., Gentili, B., Werdell, P. J., Hooker, S. B., and Franz, B. A.: Examining the consistency of products derived from various ocean color sensors in open ocean (Case 1) waters in the perspective of a multi-sensor approach, Remote Sens. Environ., 111, 69-88, 2014.

O'Carroll, A. G., Eyre, J. R., and Saunders, R. W.: Three-way error analysis between AATSR, AMSR-E and in situ Sea Surface Temperature observations, J. Atmos. Ocean. Tech., 25, 1197-1207, 2008.

Ocean \& Sea Ice SAF: Atlantic Sea Surface Temperature Product Manual, Version 1.6, October 2006.

Price, J., Weller, R., Bowers, C., and Briscoe, M. G.: Diurnal response of sea surface temperature observed at the long-term upper ocean study $\left(34^{\circ} \mathrm{N}, 70^{\circ} \mathrm{W}\right)$ in the Sargasso Sea, J. Geophys. Res., 92, 14480-14490, 1987. 
Prytherch, J., Farrar, J. T., and Weller, R. A.: Moored surface buoy observations of the diurnal warm layer, J. Geophys. Res., 118, 4553-4569, 2013.

Richter, I. and Mechoso, C. R.: Orographic influences on the annual cycle of Namibian stratocumulus clouds, Geophys. Res. Lett., 31, 1-4, doi:10.1029/2004GL020814, 2004.
Ward, B.: Near-surface ocean temperature, J. Geophys. Res. 111, C02004, doi:10.1029/2004JC002689, 2006.

Webster, P. J., Clayson, C. A., and Curry, J. A.: Clouds, radiation, and the diurnal cycle of sea surface temperature in the Tropical Western Pacific, J. Climate, 9, 1712-1730, 1996. 